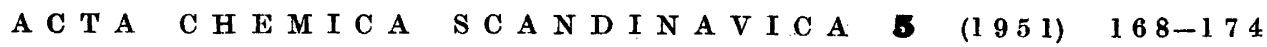

\title{
The Importance of Bivalent Ions for the Aggregate Molecular Weight of Sodium Thymonucleate in Aqueous Solution
}

\author{
G U N N A R J U N N ER
}

Biochemical Department, Karolinska Institutet, Stockholm, Sweden

B ivalent ions have in several respects unique effects on sodium thymonucleate (DNA). Amongst them is gelation on dialysis against $\mathrm{MgSO}_{4}$ in relatively strong solutions $\left(0.7\right.$ per cent) of $\mathrm{DNA}^{1}$. It has now been found that, when determining the dielectric molecular weight, very large molecular aggregates can be obtained with bivalent ions. The results of a number of experiments and studies are reported in the following. On the investigation of the occurrence of metals in DNA made on the basis of this observation a relatively high concentration of $\mathrm{Mg}$ could be demonstrated ${ }^{2}$. Special attention will therefore be directed to the effect of $\mathrm{Mg}^{++}$.

As in other studies of the dielectric properties of DNA made in this laboratory, the ellipsoid method originated by Fürth was used. The method was adapted to the determination of the anomalous dielectric dispersion by measurement of the dielectric constant (DC) at high frequencies within the radio frequency range. The computation of molecular weight, $M$, was done on the basis of the formulae that can be deduced for stiff thread molecules with transverse dipole moments, as follows:

$$
M=\frac{N \cdot k \cdot T \cdot \lambda_{\mathrm{c}}}{3 \cdot v \cdot \eta \cdot 2 \pi c \cdot \psi_{2}} \cdot \frac{\varepsilon_{\mathrm{h}}+2}{\varepsilon_{1}+2}=3.2 \cdot \frac{\lambda_{\mathrm{c}}}{v} \cdot \frac{\varepsilon_{\mathrm{h}}+2}{\varepsilon_{1}+2}
$$

The usual designations for known constants were used ( $k=$ Boltzmann's constant: $1.38 \times 10^{-16} \mathrm{ergs}$ per molecule; $N=$ Avogadro's number; $6.02 \times 10^{23}$; $T=$ the absolute temperature). $\psi_{2}=$ Perrin's form factor which can be given as 4/3 for thread molecules having a large axial ratio and rotating about the long axis; $\eta$ is the viscosity of the solvent. In addition to these constant factors in a given solution, we have $\lambda_{c}$ which is the wavelength at the centre 
of the curve of dispersion, $i . e$, the critical wavelength, and $v$ which is the specific volume. $\varepsilon_{h}$ and $\varepsilon_{1}$ are the dielectric constants at considerable distances from the actual dispersion range, $i$. e., at higher and lower frequencies respectively.

This formula is not identical with that earlier used and reported ${ }^{3}$, as Perrin's form factor was then incorrectly applied. The erroneous results thereby obtained have been corrected 4. Although later studies have shown that the first determinations were not correct, it is nevertheless a fact that the dielectric method gives a lower order of magnitude for the molecular weights of certain thread molecules with considerable transverse dipole moments than do the methods commonly used.

Reference is made to a detailed report from the laboratory ${ }^{5}$ respecting the method employed and for the improvements introduced.

\section{EXPERIMENTAL}

I. Theformation of high-molecular aggregates of DNA under the influence of $\mathrm{Mg}^{++}, \mathrm{Ca}^{++}$and $\mathrm{Zn}^{++}$

It is difficult to obtain reproducible values in the dielectric determination of the molecular weight of DNA in extremely dilute aqueous solutions. This variability is strongly accentuated under certain conditions in the presence of a number of ions, of which $\mathrm{Mg}^{++}, \mathrm{Ca}^{++}$and $\mathrm{Zn}^{++}$have been studied in this connexion. The following experiment may serve as an example of the way in which the "molecular weight" can be very greatly increased.

DNA, in a concentration of approximately 2.0 per cent, is dialyzed in a cellophane bag against re-distilled water until it is free from chloride and then for a further 24 hours. $\mathrm{MgCl}_{2}$ is added to approximately $0.05 \mathrm{~N}$ and the DNA precipitated with 5 volumes of ethanol. The precipitate is dissolved in water and once more precipitated to reduce the excess of salt. When this procedure is used for a DNA preparation made according to Hammarsten ${ }^{1}$ the effect shown in Fig. 1 is obtained. It is seen that the anomalous dielectric dispersion is displaced to longer wavelengths corresponding to an increase in the dielectric molecular weight from approximately 120000 (I) to over 500000 (II). If, after the dialysis, DNA is instead precipitated with alcohol without the presence of $\mathrm{Mg}^{++}$or similar ions (which requires the addition of, for example, $\mathrm{NaCl}$ ) the molecular weight is found to be the same as the original one.

The polarity of the molecular aggregate formed is not as high as that of DNA. It is true that measured absolutely the dipole moment increases considerably, whereas the "specific", polarity, i. e., the dipole moment per average mononucleotide, is appreciably lower. The aggregate is labile in that the specific dipole moment falls, particularly during the first few hours.

Similar effects to those of $\mathrm{Mg}^{++}$are obtained with $\mathrm{Ca}^{++}$and $\mathrm{Zn}^{++}$. The effects of the two last-mentioned are approximately equally pronounced but the course of the change in the DC with the frequency is not the same as with $\mathrm{Mg}^{++}$. Unlike $\mathrm{Mg}^{++}$in the form of the chloride, which results in a mainly theoretical course for the anomalous dispersion of 


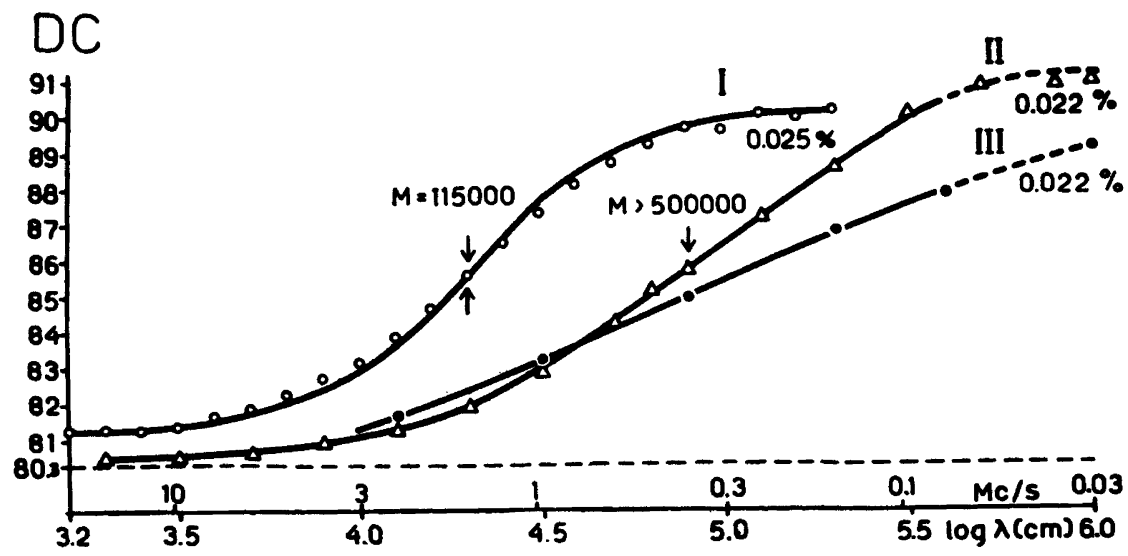

Fig. 1. Dielectric"dispersion of aggregates of thymonucleate (obtained by precipitation with ethanol in the presence of bivalent ions of sodium thymonucleate prepared according to

I Original preparation Hammarsten ${ }^{5}$ ).

II Precipitated from $0.05 \mathrm{~N} \mathrm{MgCl}_{2}$

III Precipitated from $0.05 \mathrm{~N} \mathrm{CaCl}_{2}$

Temp. $20.0^{\circ} C . D C=$ dielectric constant.

a largely monodisperse substance, $\mathrm{Ca}++$ and $\mathrm{Zn}^{++}$give a somewhat different appearance, with a slow rise at increasing wavelengths, approximately proportional to the logarithm of the wavelength. Fig. 1 shows this difference for $\mathrm{Mg}^{++}$and $\mathrm{Ca}^{++}$(II and III respectively). It is possible that some galvanic polarisation may influence the values at the longest wavelengths in the region of 10000 metres but this cannot alter the course to any great extent. The appearance of the curves for $\mathrm{Ca}^{++}$and $\mathrm{Zn}^{++}$is an expression of a pronounced dielectric polydispersion, possibly due to a gel- like structure in the solution.

The effect of $\mathrm{Ca}^{++}$and $\mathrm{Zn}^{++}$is more dominating than that of $\mathrm{MgCl}_{2}$ in the same concentration. On the other hand, it may be mentioned that $\mathrm{MgSO}_{4}$ gives the same type of dielectric dispersion as $\mathrm{CaCl}_{2}$ and $\mathrm{ZnCl}_{2}$.

\section{The effect of $\mathrm{Mg}^{++}$on the preparation of DNA}

A specimen with an extremely high aggregate molecular weight is obtained by preparing DNA from calf thymus in the presence of $\mathrm{Mg}^{++}$. With the methods of Hammarsten ${ }^{1}$ and Gulland, Jordan and Taylor ${ }^{6}$ use is made, inter alia, of treatment with $\mathrm{NaCl}$ in a strong concentration. Since this could be expected to expel the $\mathbf{M g}^{++}$it was considered advisable to investigate the matter *.

* The results of further experiments have meanwhile been published by I. Jungner ${ }^{5}$. In the present report there will only be given some basic results that are of importance in this connexion. 


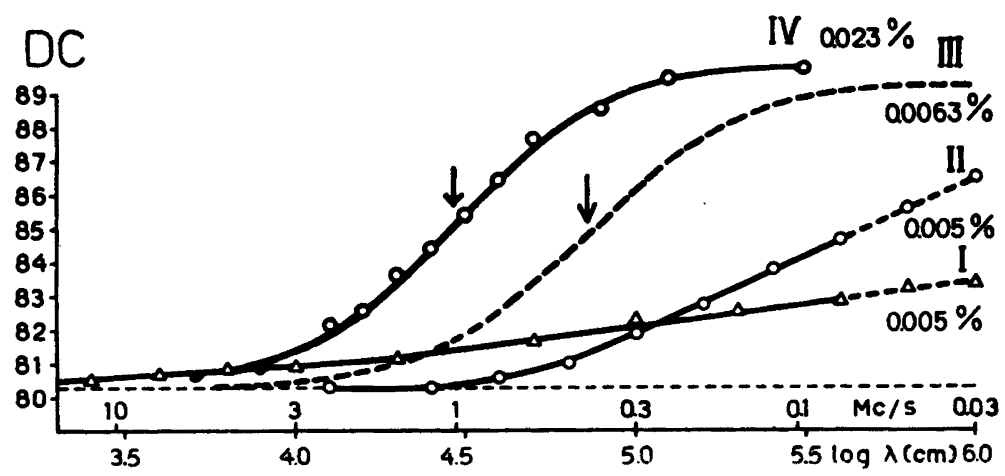

Fig. 2. Dielectric dispersion of thymonucleate prepared according to Gulland et a $\mathbf{l}^{6}$ but in the presence of $\mathrm{MgCl}_{2}$.
I Specimen prepared with $2 \mathrm{~N} \mathrm{MgCl}_{2}$ (only)
II Specimen prepared with $0.05 \mathrm{~N} \mathrm{MgCl}_{2}$ in $10 \% \mathrm{NaCl}$
III Original preparation (without $\mathrm{MgCl}_{2}$ )
IV Specimen I after treatment with half-saturated $\mathrm{NaCl}$ for 5 days.

Fig. 2 shows the results of some experiments on the production of DNA from calf thymus with the method of Gulland et al. but in the presence of $\mathrm{MgCl}_{2}$. Experiments were made both with the addition of $0.05 \mathrm{~N} \mathrm{MgCl}_{2}$ (curve II) to the prescribed concentration of $\mathrm{NaCl}(10 \%)$ and with the substitution of $2 \mathrm{~N} \mathrm{MgCl}$ for the $\mathrm{NaCl}$ (curve I). It is seen from the figure that there is then an extremely pronounced increase in the dielectric aggregate weight from that usually obtained of about 600000 (III) but that the preparations are pronouncedly polydisperse and hard to define. With the apparatus available it was only possible to study the beginning of the anomalous dielectric dispersion. The lowest molecular weights that could be estimated from these measurements were of the magnitude of several millions. The preparations were still more labile than those obtained on precipitation in the presence of $\mathrm{Mg}^{++}$and similar ions.

iil. The influence of the Mge concentration on the formation of high-molecular aggregates

Some experiments have been made to investigate the minimum $\mathrm{Mg}^{++}$concentration necessary to get formation of the aggregates. Dialysed specimens of DNA (prepared according to Hammarsten ${ }^{1}$ ) were precipitated by ethanol in the presence of various $\mathrm{Mg}^{++}$concentrations. The reproducibility is not, however, always good. This is presumably due to the great sensitivity of the precipitation mechanism. A low $\mathrm{NaCl}$ content is necessary to get precipitation by ethanol. Fig. 3 shows the results in diagram. The dielectric dispersion for the original preparation is not included since this is impossible to differentiate significantly from the curve obtained with $10^{-4} \mathrm{~N} \mathrm{MgCl}_{2}$. The effect of $10^{-8}$ $\mathrm{N} \mathrm{MgCl}$ is obvious (but badly reproducible) and is still more pronounced in $10^{-2} \mathrm{~N} \mathrm{MgCl}_{2}$. At higher concentrations no further tendency to give larger aggregates is obtained (cf., curve II in Fig. 1, obtained with $0.05 \mathrm{~N} \mathrm{MgCl}_{2}$ ). 


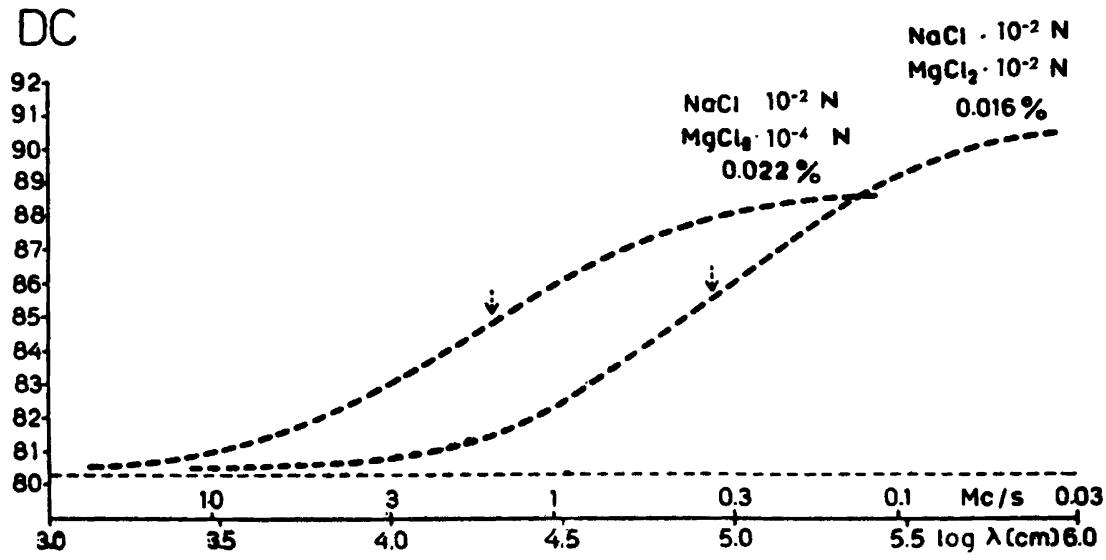

Fig. 3. Dielectric dispersion of DNA, precipitated in the presence of small concentrations of $\mathrm{MgCl}_{2}$. (See text.)

\section{On the presence of $M g$ in DNA}

It is found that the greater part of the original Mg content in DNA (about 0.1 per cent ${ }^{2}$ ) can be eliminated by dialysis. A further quantity of $\mathrm{Mg}$ is removed on treatment with $\mathrm{NaCl}$, e.g., $0.5 \mathrm{~N}$. The residual $\mathrm{Mg}$ content (<0.01 per cent) is difficult to deal with. It can, however, be decreased by acid hydrolysis and then only occurs in traces as do metals of other kinds. The magnesium contents were estimated in the experiments by means of spectral analyses and spot tests (e.g., Titan Yellow).

\section{Reversibility of the action of Mg}

DNA prepared according to Gulland et al ${ }^{6}$, but with $2 \mathrm{~N} \mathrm{MgCl}_{2}$ instead of 10 per cent $\mathrm{NaCl}$ (curve 1, Fig. 2), was treated with half-saturated $\mathrm{NaCl}$ for 5 days. After repeated precipitations with ethanol it was reinvestigated dielectrically. As shown in fig. 2 (curve IV), there is now obtained a well-defined dispersion curve with a high increment at considerably shorter wave-lengths. In fact, the aggregate weight - about 200000 - is considerably smaller than that found for an original preparation according to Gulland et al. without addition of $\mathrm{Mg}$ (curve III, Fig. 2, page 171).

\section{DISCUSSION}

Bivalent ions have evidently a considerable effect on aggregate conditions of DNA. $\mathrm{Mg}$ is of particular interest in this connexion and various stages of its effect on DNA can be distinguished. First, there is a non-specific electrolyte effect similar to that obtained with other cations ${ }^{1,5}$. Under these conditions, 
when $\mathrm{Mg}^{++}$is added to dilute aqueous solutions of DNA, disaggregation results ${ }^{5}$. The inter-molecular distances are presumably too large to permit an aggregating effect but in stronger concentrations of DNA, as in Hammarsten's experiments ${ }^{1}$ (with 0.7 per cent) or on precipitation with alcohol, conditions for the formation of aggregates are present.

Secondly, $\mathrm{Mg}^{++}$can enter the phosphoric acid groups instead of $\mathrm{Na}^{+}$but can possibly also enter less acid radicals. Such an exchange of ions must certainly take place in such a polybasic acid as thymonucleic acid. It can be assumed that the bivalent ions studied, on precipitation with alcohol, bring about the large aggregates and possibly a gel formation owing to linking various molecules. The aggregate formation is presumably non-specific. Its reversibility by means of $\mathrm{NaCl}$ implies that we are dealing with an exchange of ions.

Thirdly, there is a more resistant $\mathrm{Mg}$ content of DNA, and this may indicate that $\mathrm{Mg}$ also is bound in a non-ionic way.

From the experiments with preparations of DNA it appeares possible to neutralize in the presence of $\mathrm{Mg}^{++}$a possible effect on the aggregate molecular weight by treatment with $\mathrm{NaCl}$.

The experiments indicate that the molecular aggregates obtained are to be regarded as mainly artificial products. Nevertheless, these aggregates presumably also contain such polarly associated components as may have been built up in an analogous way to the original molecules. Thus, it may be considered that $\mathrm{Mg}^{++}$and similar metals may be of importance for the formation of the DNA macromolecule.

\section{SUMMARY}

Large molecular aggregates are obtained on precipitation of sodium thymonucleate (DNA) from aqueous solution with ethanol in the presence of a number of bivalent ions $\left(\mathrm{Mg}^{++}, \mathrm{Ca}^{++}\right.$and $\left.\mathrm{Zn}^{++}\right)$. In analogy herewith, preparations with very high molecular weights (several millions) are obtained on the production of sodium thymonucleate in the presence of $\mathrm{Mg}^{++}$.

The aggregates produced seem not to have the same high polarity as that characterizing sodium thymonucleate in the original state. The bivalent ions can be expelled to some extent by means of treatment with strong sodium chloride solution. Smaller molecular weights are then obtained, down to about 200000 .

It should be noted that all molecular weights mentioned are determined by a dielectric method which gives relatively lower values for DNA than those obtained by other methods. 
The results are discussed in view of the possibility that the bivalent ionsand in particular $\mathrm{Mg}$ - can be of importance for the formation of the DNA macromolecule.

\section{REFERENCES}

1. Hammarsten, E. Biochem. Z. 144 (1924) 383.

2. Jungner, G. Science (in press).

3. Jungner, G. Acta Physiol. Scandinav. 10 (1945) Suppl. 32.

4. Jungner, G., Jungner, I., and Allgén, L-G. Nature 163 (1949) 849.

5. Jungner, I. Acta Physiol. Scandinav. (1950) Suppl. 69.

6. Gulland, J. M., Jordan, D. O., and Threlfall, C. J. J. Chem. Soc. (1947) 1129.

Received November 10, 1950. 